\title{
Terra Brasil: cultura e ensino em livro didático de português para estrangeiros
}

\author{
Henrique Rodrigues Leroy \\ CEFET-MG \\ Jerônimo Coura Sobrinho \\ CEFET-MG
}

\begin{abstract}
Resumo
O livro didático de língua estrangeira representa um papel decisivo na construção do imaginário cultural do aprendiz. Muitas vezes o primeiro contato com a língua-cultura alvo dá-se por meio do livro didático. Daí a importância que esse veículo tem na constituição da cultura do aprendiz. O presente trabalho tem o objetivo de refletir sobre tarefas culturais propostas no livro didático Terra Brasil: curso de Língua e Cultura, verificando se as mesmas são contempladas pelo quadro de abordagens de ensino de cultura propostas por Gimenez (2002). A essas interpretações sobre o ensino de cultura, somam-se quatro categorias de cultura desenvolvidas por Moran (1990) e adaptadas por Fontes (2002). Portanto, este trabalho pretende estimular a criação de um lugar intercultural, onde o aprendiz e o professor de PLE se sensibilizam por meio de um olhar crítico e cultural, para as suas próprias visões de mundo, ao descobrirem-se capazes de aceitar e respeitar o outro no espaço da interculturalidade.
\end{abstract}

Palavras- Chave: Cultura; Abordagens de Ensino de Cultura em PLE; Livro didático

\begin{abstract}
The foreign language course book has a crucial role in the construction of a learner's cultural imagination. The first contact with the target language often comes from the textbook itself, and this is the reason for its importance in the learner's construction of culture. The objective of this paper is to reflect on cultural tasks in the Terra Brasil: curso de lingua e cultura course book. The study aims to verify whether the tasks fit Gimenez's (2002) table of approaches to teaching culture. The study also uses the four categories of culture proposed by Moran (1990), and adapted by Fontes (2002). Thus, this paper intends to encourage the creation of an intercultural place, where the learner and teacher of Portuguese as a foreign language will become interculturally sensitive by means of a critical and cultural perspective in relation to their own world views, when they realize that they are able to accept and respect the intercultural space of others.

Keywords: Culture, Teaching culture approaches in Portuguese for foreigners, textbook.
\end{abstract}




\section{CONSIDERAÇÕES INICIAIS}

O julgamento de valor é inerente ao ser humano. As pessoas fazem uso dele nas mais variadas situações e contextos. Quando assistem ao noticiário, emitem suas opiniões sobre determinado assunto ou pessoa com base no que foi transmitido. Ao lerem um romance, constroem suas opiniões e pensamentos a respeito do enredo ou do personagem a partir da informação exposta pelo narrador. Quando assistem a um documentário sobre o Brasil, constroem suas imagens de Brasil de acordo com o conteúdo ali exposto. Não raro, esse julgamento de valor pode vir agregado de estereótipos, pré-conceitos e conhecimentos prévios dos mais variados temas. Vários são os veículos que incitam essa prática, como por exemplo, a televisão, o livro, o cinema, a internet.

$\mathrm{Na}$ sala de aula da variante brasileira da língua portuguesa para estrangeiros (PLE) essa prática não é diferente. Muitas vezes, o único contato que o aluno tem com a língua-cultura-alvo é por meio do livro didático ou de outros materiais desenvolvidos para a aula. Isso faz com que o livro didático exerça importante papel na construção das imagens, pensamentos e julgamentos do aprendiz em relação à cultura aprendida, isto é, a brasileira. Esse veículo, ou o livro didático, que estimula o aluno a fazer o seu julgamento de valor, está reforçando ou desconstruindo o estereótipo que ele tem da cultura brasileira? Além disso, as tarefas culturais presentes no livro didático sensibilizam o aprendiz para uma visão de mundo crítica com base na interação da sua identidade cultural com a identidade cultural do outro? $\mathrm{O}$ aluno se sente preparado para se comunicar em situações que envolvem o uso da variante brasileira da língua portuguesa? Essas situações de uso refletem traços da competência intercultural do aprendiz?

A partir desses questionamentos, pretende-se, primeiramente, promover uma reflexão sobre o papel da cultura no ensino de PLE. Para tanto, apresentaremos alguns conceitos de cultura e faremos uma opção por um deles, para o desenvolvimento deste trabalho. A seguir, descreveremos as abordagens de ensino de cultura (Gimenez, 2002) brevemente, com ênfase para a abordagem intercultural, que abrange toda a reflexão. Ainda no campo teórico, destacaremos o papel que o livro didático de língua estrangeira representa no mundo da cultura. Discutiremos também duas tarefas do livro didático de PLE Terra Brasil: curso de língua e cultura (TB) (Almeida \& Dell'ísola, 2008). Na discussão do corpus, levaremos em conta duas categorias - ensino e cultura - (Moran 
apud Fontes, 2002). Merece destaque, no âmbito das análises, o papel fundamental que o professor sensibilizado interculturalmente exerce na aplicação dessas tarefas em sala de aula. Por fim, teceremos considerações a respeito do ensino intercultural em PLE, observando se as mesmas podem possibilitar ao aprendiz o desenvolvimento de uma competência intercultural efetiva no que concerne ao uso da variante brasileira da língua portuguesa.

\section{DEFINIÇÕES DE CULTURA E O PAPEL DA CULTURA NO ENSINO DE PLE}

Segundo Zanatta (2009), um dos primeiros conceitos de cultura foi definido pelo teórico inglês Tylor. De acordo com Silva (1986), Tylor afirmou que “cultura é o conjunto de conhecimentos, crenças, arte, moral, leis, costumes, enfim, todo comportamento ou situação aprendida, herdada do núcleo familiar, dos antepassados, da sociedade." (Silva, 1986 in Zanatta, 2009:161). Zanatta (2009) ainda afirma que, a partir dessa definição, outros estudos sobre cultura começaram a surgir, dando a devida importância a tão amplo vocábulo.

A ideia de que a cultura diversifica e enriquece a humanidade, apesar de o homem ser essencialmente e biologicamente cultural, surgiu a partir dos primeiros estudos de Tylor. Assim, a cultura, no seu sentido educacional e instrucional, traz polidez ao comportamento dos indivíduos por meio da aprendizagem vivenciada desde a infância até a fase adulta. A cultura pensada como tal contempla a maneira que o homem pensa e age sobre o mundo que o cerca. Portanto, a cultura é vista como um processo acumulativo de sistemas e símbolos interdependentes que o homem agrega para si ao longo de seu processo evolutivo. Tal processo dinâmico e mutante tem o poder de agir sobre o comportamento e hábito humanos. Esse processo, que assiste o homem na compreensão de si mesmo e na previsão de seus comportamentos, é reconhecido somente por meio do contexto cultural específico onde ele está inserido. Tudo isso amplia ainda mais o conceito que se tem de cultura. Cultura e ser humano são tão intrínsecos um ao outro que discutir cultura seria sinônimo de pensar a própria natureza humana.

Consequentemente, adota-se para o presente trabalho, o conceito de cultura como um fator constituinte e inerente à linguagem humana, corroborando assim o aspecto indissociável entre língua e cultura. Tal conceito é também contemplado nos 
pressupostos teóricos do Exame de Proficiência em Língua Portuguesa para Estrangeiros (Celpe-Bras):

\begin{abstract}
No que se refere à questão cultural, entende-se por cultura as experiências de mundo e as práticas compartilhadas pelos membros de uma comunidade. Os indivíduos agem em contexto e, como tal, são influenciados por sua própria bibliografia e pelo contexto social e histórico no qual estão inseridos. Cultura não é vista aqui como uma lista de fatos, autores ou datas importantes, mas como vários processos culturais inter-relacionados, tais como formas de interagir em diversas situações e contextos, atribuições de valores, representações de si próprio e do outro, modos de relacionar a interação e a organização cotidiana com sistemas e processos culturais mais amplos. Cultura não é algo acabado, mas co-construído nas práticas cotidianas de uma comunidade. Levar em conta a cultura brasileira no exame Celpe-Bras significa, portanto, estar sensibilizado para outros pontos de vista sobre o mundo e para atribuir sentidos, considerando a situação da interação oral e/ou escrita. (Ministério da Educação, 2006:4)
\end{abstract}

Ao tocar na sensibilização para outros pontos de vista sobre o mundo a fim de produzir sentidos, uma breve discussão sobre os termos multicultural e intercultural é necessária. Zanatta (2009) indica que o termo multicultural é definido de duas maneiras. A primeira está ligada ao coletivo, às sociedades multiculturais como a coexistência de pessoas de diferentes backgrounds e etnias. A segunda forma está voltada para o indivíduo, uma vez que os vários recursos linguísticos e estratégias sociais são utilizados por diferentes pessoas pertencentes a várias comunidades discursivas, a fim de afiliar-se e identificar-se com outras culturas distintas e outras formas de uso da língua. Portanto, segundo a autora, "a identidade cultural dos indivíduos multiculturais é composta por uma multiplicidade de papéis sociais ou posições que o sujeito ocupa seletivamente, dependendo do contexto interativo no qual se encontra inserido." (Zanatta, 2009:162) Por outro lado, o termo intercultural sobrepõe-se ao multicultural no que concerne ao fato de referir-se à comunicação e interação entre pessoas de diferentes culturas étnicas, sociais e de sexo, inserido nos limites da mesma língua nacional. Soma-se a isso o fato da interculturalidade também se referir ao encontro de duas culturas ou duas línguas por intermédio das fronteiras políticas de suas nações. Um conceito não exclui o outro. Pelo contrário, eles reforçam a idéia de que as culturas não são monolíticas, ou seja, a prática intercultural evoca um saber coletivo maior, que por sua vez, aciona os diversos indivíduos multiculturais que compõem uma sociedade cada vez mais mutante, dinâmica e plural.

Entende-se, portanto, que o papel da cultura no ensino de PLE deve estar atrelado ao entendimento de que língua e cultura são indissociáveis. Para Ferreira (1998), o ensino 
de uma língua estrangeira é um importante fator de interculturalidade, já que a língua, ao mesmo tempo em que produz e veicula a cultura, é o instrumento através do qual se realizam apropriação e trocas culturais. A língua permite ao ser humano não apenas satisfazer a sua necessidade de comunicação, mas também realizar a sua comunhão com o outro, criando um clima favorável à coexistência, ao intercâmbio, ao diálogo e à solidariedade.

\section{ABORDAGENS SOBRE O ENSINO DE CULTURA}

Com o intuito de compreender o papel que a cultura representa na sala de aula de PLE, estudos da Linguística Aplicada apontam três maneiras de se abordar a cultura nesse contexto. A seguir, apresenta-se a visão de cultura, língua e ensino desenvolvida por Gimenez (2002) em três abordagens: a tradicional, a cultura como prática social e a intercultural.

\section{Abordagem tradicional}

$\mathrm{Na}$ abordagem tradicional a cultura é representada como produtos culturais. Então, toda e qualquer forma de arte, como as artes plásticas, a música, a literatura, o cinema são considerados cultura. Nessa abordagem, a língua não está vinculada à cultura e a aprendizagem e o ensino da cultura dão-se pela aprendizagem dos fatos. Por exemplo, como tarefa, um professor pede aos alunos para irem à biblioteca pesquisar sobre o que os brasileiros comem no jantar. De acordo com Gimenez (2002), essa é uma visão monolítica da cultura, pois não podemos definir a cultura de um povo de uma única forma, principalmente se essa forma for estereotipada.

\section{Abordagem da cultura como prática social}

Nessa abordagem, a cultura é interpretada como um modo de agir coletivo por intermédio da linguagem. Assim, língua e ensino estão ligados à cultura no que concerne ao pensar e agir do outro. Por exemplo, ao se aproximarem as festas juninas, toda a escola é decorada com bandeirolas, balões de São João e fogueiras e os professores encorajam os alunos a vestirem os trajes típicos para dançarem uma quadrilha. Para Gimenez (2002), essa perspectiva avança no sentido de gerar compreensão da relatividade dos sentidos imbricados nas práticas culturais. Para a autora, 
Culturas são vistas como favorecendo modos diretos ou indiretos de falar, de organizar textos de modos específicos. Esta visão deixa o aluno com seu próprio paradigma cultural, observando e interpretando palavras e ações de um interlocutor a partir de um outro paradigma cultural. A competência cultural é entendida como o conhecimento sobre o que um determinado grupo cultural e entendimento dos valores culturais sobre determinadas formas de agir ou sobre certas crenças. Ao invés de só olhar o outro, o aprendiz se olha também, mas permanece com a idéia de que para comunicar-se adequadamente na língua estrangeira, deve olhar o mundo como o estrangeiro. (Gimenez, 2002:4)

\begin{abstract}
Abordagem Intercultural
Quatro são os termos presentes na abordagem intercultural que remete ao pensamento de como ensinar língua e cultura. De acordo com Kramsch (1993 apud Gimenez, 2002), a abordagem intercultural, também conhecida como a abordagem do espaço intermediário, propõe:
\end{abstract}

1. Estabelecimento de uma esfera de interculturalidade, diferente de transferência de informação entre culturas. Inclui reflexão sobre a cultura nativa $(\mathrm{C} 1)$ e a culturaalvo (C2).

2. Ensino de cultura como um processo interpessoal - substituir a apresentação/prescrição de fatos culturais e comportamentos pelo ensino de um processo que se aplica ao entendimento do que seja ser "estrangeiro", ou "alteridade" (otherness).

3. Ensino de cultura como diferença - não tratar cultura como características nacionais como se identidades nacionais fossem monolíticas. Em cada cultura há uma variedade de fatores relacionados à idade, gênero, origem regional, background étnico e classe social.

4. Cruzamento de fronteiras disciplinares - encorajar professores a expandirem seus horizontes de leituras para além da literatura, lendo estudos de cientistas sociais, etnógrafos, e sociolinguistas tanto sobre sua sociedade quanto sobre as sociedades que falam a língua que ensinam.

Para aplicação de tal perspectiva, Kramsch (1993) propõe quatro etapas:

1. Reconstruir o contexto de produção e recepção do texto dentro da cultura estrangeira (C2 e percepções de C2);

2. Construir com os alunos seu próprio contexto de recepção, i.e. encontrar um fenômeno equivalente em $\mathrm{C} 1$ e construir o fenômeno na $\mathrm{C} 1$ com suas próprias redes de significado; 
3. Examinar o modo como as percepções de $\mathrm{C} 1$ e $\mathrm{C} 2$ em parte determinam as percepções que estrangeiros têm delas, i.e. o modo como cada cultura vê a outra;

4. Preparar o terreno para um diálogo que poderia levar à mudança.

De acordo com Lo Bianco, Liddicoat e Crozet (1999), um falante de PLE interculturalmente competente apresenta competência linguística e conscientização sociolinguística sensibilizadas à língua e ao contexto onde ela é falada, à interação pelas fronteiras culturais, à previsão de mal-entendidos, devido às diferenças de valores, significados e crenças, a fim de lidar com as exigências cognitivas e afetivas advindas do contato com o outro. Nas palavras de Zanatta (2009:164), "os objetivos do ensino intercultural envolvem a aprendizagem sobre a cultura, a comparação entre elas e a exploração do seu significado." Isso indica um envolvimento no que concerne às abordagens tradicional e de cultura como prática social para além da simples comparação, fazendo com que o aprendiz constate e entenda as diferenças culturais, levando-o a refletir sobre sua própria visão de mundo. Neste sentido,

A diferença entre ser um escravo de suas próprias fronteiras culturais ou ser livre delas não está na negação das próprias fronteiras (por ex. através da adoção de outra cultura ou da imitação de códigos culturais estrangeiros), mas na consciência de onde estão essas fronteiras (Crozet, Liddicoat \& Lo Bianco (1999:13).

A seguir, o quadro explicativo sobre as abordagens de ensino e cultura com suas respectivas visões de cultura, língua e ensino (Gimenez, 2002) é apresentado:

Quadro 1 - Abordagens de ensino de cultura (GIMENEZ, 2002:3)

\begin{tabular}{|c|c|c|c|}
\hline ASPECTO & $\begin{array}{l}\text { ABORDAGEM } \\
\text { TRADICIONAL }\end{array}$ & $\begin{array}{l}\text { CULTURA COMO } \\
\text { PRÁTICA SOCIAL }\end{array}$ & $\begin{array}{c}\text { ABORDAGEM } \\
\text { INTERCULTURAL }\end{array}$ \\
\hline Cultura & $\begin{array}{c}\text { Produtos culturais, } \\
\text { e.g. literatura, artes, } \\
\text { música }\end{array}$ & $\begin{array}{c}\text { Modo de agir } \\
\text { coletivo através da } \\
\text { linguagem }\end{array}$ & $\begin{array}{l}\text { Modo de ver o } \\
\text { mundo }\end{array}$ \\
\hline Língua & $\begin{array}{l}\text { Desvinculada de } \\
\text { cultura }\end{array}$ & $\begin{array}{c}\text { Estreitamente ligada } \\
\text { à cultura }\end{array}$ & Língua é cultura \\
\hline Ensino & $\begin{array}{c}\text { Aprendizagem sobre } \\
\text { fatos }\end{array}$ & $\begin{array}{l}\text { Aprendizagem sobre } \\
\text { modos de pensar e } \\
\text { agir do Outro }\end{array}$ & $\begin{array}{l}\text { Exploração de um } \\
\text { espaço intermediário, } \\
\text { pelo contraste entre a } \\
\text { linguacultura própria } \\
\text { e linguacultura-alvo. }\end{array}$ \\
\hline
\end{tabular}




\section{O LIVRO DIDÁTICO DE LÍNGUA ESTRANGEIRA: SEU PAPEL COMO OBJETO CULTURAL}

De acordo com Batista (1998), relações complexas são estabelecidas entre a escola, o livro didático e o mundo da cultura. Apesar de Batista (1998) tratar do livro didático de língua materna, cujos público-alvo e propósitos são distintos de um livro didático de língua estrangeira, que é o perfil do Terra Brasil, suas concepções sobre o papel do livro didático como objeto cultural também podem ser aplicados ao livro didático de língua estrangeira. Pensa-se que o livro didático e a escola condensam ou simplesmente adaptam os saberes produzidos pelo mundo que está fora dos limites escolares, ou seja, pelo mundo da cultura, para serem transmitidos em sala de aula. Entretanto, estudos investigativos apontam para a complexidade da origem desses saberes e objetos (Bittencourt, 1993). Segundo esses estudos, a origem desses saberes está justamente na escola e nos livros didáticos por ela utilizados. Por exemplo, os manuais didáticos de história brasileira do século XIX e do início do século XX, apesar de serem direcionados para alunos do Ensino Médio, acabam por extrapolar os limites da escola, transformando-se em referência para o "grande público" e para outras obras clássicas da história da interpretação do Brasil. Assim, esse objeto cultural, que é o livro didático, assume importante papel na cultura brasileira, nas práticas de letramento e nas produções editoriais. Ele compreende diferentes dimensões de nossa cultura, podendo ser, ao mesmo tempo, produtor e veiculador dos mais variados aspectos culturais.

Nas próximas seções descrevo o objeto de análise deste artigo, o livro Terra Brasil: curso de língua e cultura (Almeida \& Dell'ísola, 2008), bem como as atividades que serão analisadas.

\section{TERRA BRASIL: CURSO DE LÍNGUA E CULTURA.}

Para Almeida e Dell'Ísola (2008), TB destina-se a falantes de qualquer idioma que queiram aprender a variante brasileira da Língua Portuguesa. Esse livro-texto destina-se a alunos iniciantes e também àqueles que já tenham algum conhecimento do idioma. As primeiras unidades ( 1 a 4) têm como público-alvo os principiantes, sem conhecimento do Português. As demais unidades (5 a 12) destinam-se a alunos que têm conhecimento básico sobre a Língua Portuguesa e querem se aperfeiçoar. 
No título de TB, destaca-se o vocábulo cultura, uma vez que é de interesse das autoras inserir os aprendizes estrangeiros na língua-cultura alvo em questão, por meio da prática e uso da variante brasileira da língua portuguesa. Espera-se que essa práxis seja concretizada nas atividades das seções Diálogo, Na ponta da língua, Guarde bem, Bate-papo, Sistematizar é preciso..., Leio, logo entendo, Ouça bem!, Sons da $\underline{\text { Terra }}$, Desafio: tarefa comunicativa, Almamaque Brasil, Consultório Gramatical,

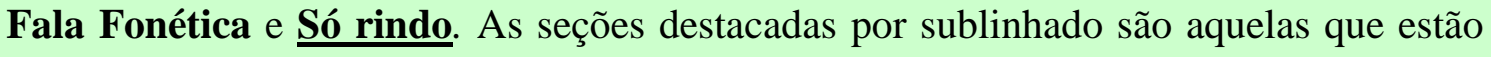
diretamente relacionadas à cultura e aos aspectos interculturais presentes no manual didático.

Neste artigo serão descritas apenas as seções "Desafio: tarefa comunicativa" e “Almanaque Brasil", pois contemplam as atividades que serão analisadas. De acordo com as autoras de TB, as tarefas de "Desafio: tarefa comunicativa" pertencem a um contexto de comunicação que conduz o estudante à percepção e ao ajuste do registro linguístico de acordo com as diferentes situações comunicativas. As atividades elaboradas nesse tópico estão de acordo com os princípios que regem o exame de proficiência Celpe-Bras. Assim, o livro não se limita a oferecer enunciados isolados para que o aprendiz focalize a estrutura da língua; oferece, além disso, a oportunidade de o estudante executar diferentes tarefas comunicativas em que as formas aprendidas poderão ser utilizadas. Essa seção tem como objetivo levar o aprendiz a usar a língua portuguesa de forma semelhante à maneira que os falantes nativos a utilizariam. Portanto, trata-se de uma ação com um propósito direcionado a um ou mais interlocutores. Já na seção "Almanaque Brasil”, podem ser observados costumes e traços característicos e populares do povo brasileiro. Esse tópico compreende aspectos culturais brasileiros, em pequenos textos sobre família, comportamento, esporte, lazer, território nacional e outros temas que traçam o perfil da sociedade brasileira. O aprendiz é convidado a pesquisar um pouco mais sobre o país: sua história, hábitos e cultura. Essas tarefas, após analisadas, serão aplicadas em contexto e imersão e não imersão.

\section{As tarefas}

Todas as seções da Unidade 8 de TB, intitulada "O superatleta", são construídas com base em diversas modalidades de esporte e atividades físicas. Na seção "Desafio: tarefa comunicativa", p. 196, o assunto é futebol. A seguir, a tarefa: 
Você já ouviu esses termos: "na trave", "pisar na bola", "ficar para escanteio"? Procure saber como essas expressões são empregadas fora do campo de futebol, na linguagem diária dos brasileiros. Em grupo, faça uma pesquisa do significado desses e de outros termos futebolísticos usados de modo figurado. Em seguida, faça um glossário com os significados encontrados. Vamos reunir todos e, no próximo encontro, fazer um minidicionário?

A Unidade 10 de TB, intitulada "Entrevista", é sobre o mundo das celebridades. A seção "Almanaque Brasil”, p. 248-249, é sobre as novelas brasileiras. Um texto, intitulado "A novela brasileira: entre a tela e a vida real", de Sanches e Lima (1997), publicado na "Revista Veja" (veja anexo) é apresentado antes da instrução da tarefa, que é a seguinte:

Acesse o site http://www.redeglobo.com, clique em entretenimento, escolha um dos títulos de novela, leia sobre os capítulos da semana e escreva um resumo. Traga para contar aos colegas, no nosso próximo encontro.

\section{METODOLOGIA}

Este trabalho apresenta uma metodologia de caráter exploratório e interpretativista, uma vez que serão descritas tarefas propostas por TB com base em categorias de análise específicas. As tarefas presentes nas seções "Desafio: tarefa comunicativa", p. 196, e “Almanaque Brasil”, p. 248-249, serão discutidas, verificando se as mesmas são contempladas pelo quadro de abordagens de ensino de cultura (Gimenez, 2002) associadas às categorias de cultura (Moran apud Fontes, 2002). Optamos por usar o quadro de abordagens de ensino de cultura juntamente às categorias de cultura como embasamento para as análises porque acreditamos que estas ajudam a desvendar e explicar cada abordagem de ensino. A seguir, as categorias de cultura, bem como o quadro que associa as abordagens de ensino de cultura com as respectivas categorias de análise são expostos. 


\section{As categorias de análise e o quadro que associa abordagens e categorias de cultura}

As categorias de análise descritas por Moran (apud Fontes, 2002) são as seguintes:

\section{Cultura, como saber sobre}

Esta categoria inclui todos os aspectos culturais que constituem informações atos, dados, fatos, conhecimentos. Para ela, os alunos precisam possuir informações sobre cultura. De acordo com a natureza do conteúdo, informações são pedidas como qual é a capital do Brasil e temas relacionados ao futebol como o esporte favorito dos brasileiros. O objetivo da aprendizagem é demonstrar o domínio das informações. As atividades referem-se às leituras de textos com enfoque cultural, filmes e dvds, gravações, relatos pessoais. É desta forma que a cultura-alvo brasileira é tradicionalmente ensinada. Os alunos recebem as informações e mostram seu conhecimento (ou não) sobre elas. O papel do professor é fornecer informações.

\section{Cultura, como saber como}

Esta categoria inclui os aspectos culturais que constituem habilidades - ações, participações, comportamentos. Assim, contempla-se a participação direta ou simulada na vida diária das pessoas da cultura-alvo, de acordo com seus costumes e tradições, usando seus instrumentos e sua tecnologia, estabelecendo relações eficazes com elas. Os alunos precisam ser capazes de se adaptar/integrar à cultura - dizer e fazer coisas à maneira dos brasileiros. Isso significa mudar seus comportamentos. De acordo com a natureza do conteúdo, algumas habilidades são esperadas como comprar um ingresso para um jogo de futebol ou comportar-se como um brasileiro durante um jogo de futebol. O objetivo da aprendizagem é demonstrar uma habilidade, uma especialidade, confiança e naturalidade por meio da aplicação de atividades, diálogos, dramatizações e

simulações. É aqui que ocorre a competência comunicativa envolvendo língua e cultura. Os alunos sabem o que dizer e como dizer de uma maneira culturalmente apropriada. $\mathrm{O}$ papel do professor é o de treinador ou modelo.

\section{Cultura, como saber por quê}

Este aspecto trata da compreensão dos valores básicos, das atitudes e suposições da cultura: as razões que fundamentam e permeiam todos os aspectos da cultura. Esse processo de indagação dos alunos sobre observações, informações e experiências com a 
cultura é uma dimensão crítica da aprendizagem de uma nova cultura. Os alunos precisam entender a cultura por ela mesma. Os valores básicos de uma cultura-alvo são importantes pontos de comparação com os valores da cultura dos alunos. Há necessidade de desenvolver habilidades para investigar, articular e analisar. Valores e suposições como por que os brasileiros gostam tanto de futebol e se você está fazendo uma observação ou uma interpretação destes valores são observados. Os objetivos da aprendizagem apresentados são: demonstrar habilidades para inferir, generalizar, fazer hipóteses, ser objetivo. Demonstrar curiosidade, tolerância, sensibilidade e interpretar e tirar conclusões com base nas atividades anteriores, fazer comparações com sua própria cultura e escrever com reflexão são atividades dessa categoria de cultura. Aqui os alunos usam vigorosamente seus poderes de indução, análise e intuição para tirar conclusões sobre as informações ou experiências culturais. O papel do professor é o de questionar e fornecer informações.

\section{Cultura, como conhecer a si mesmo}

Este aspecto trata do aluno individualmente - seus valores, suas opiniões, seus sentimentos, seus questionamentos, suas reações, seus pensamentos e suas idéias, seus próprios valores culturais. Trata do autoconhecimento. Os alunos precisam entender a si mesmos e a sua própria cultura como um meio para compreender, adaptar-se ou integrar-se à nova cultura. São eles que decidem até que ponto aceitam, exploram ou tornam-se parte da cultura. No que concerne ao autoconhecimento, os aprendizes refletem sobre a importância que os esportes têm em suas vidas e sobre como eles se sentem ao agir como um brasileiro durante um jogo de futebol. Por meio de comportamentos/afirmações, os alunos demonstram compreensão de sentimentos, seus valores, suas opiniões e atitudes. Como atividades, os alunos examinam e falam sobre si mesmos, escrevem com reflexão e retornam às atividades anteriores. Os próprios alunos são tema da discussão em um processo de autodescobrimento orientado, à medida que estudam seus próprios valores e suas reações àqueles da cultura-alvo. Eles decidem se querem mudar ou não. O papel do professor é orientar.

O quadro abaixo (Zanatta, 2009) ilustra o paralelo estabelecido entre as classificações das abordagens de ensino de cultura de Gimenez (2002) e das categorias de cultura de Moran (apud Fontes, 2002). É com base nesse quadro que as tarefas presentes nas seções "Desafio: tarefa comunicativa" e "Almanaque Brasil” de TB serão discutidas. 
Quadro 2 (ZANATTA, 2009:165) - Abordagens de ensino de cultura (GIMENEZ, 2002) associadas às categorias de cultura de Moran (apud FONTES, 2002)

\begin{tabular}{|c|c|c|c|}
\hline & $\begin{array}{l}\text { Abordagem } \\
\text { Tradicional }\end{array}$ & $\begin{array}{l}\text { Cultura como } \\
\text { prática social }\end{array}$ & Intercultural \\
\hline $\begin{array}{c}\text { MORAN } \\
\text { (1990) }\end{array}$ & $\begin{array}{l}\text { 1) Cultura, como } \\
\text { saber sobre: inclui } \\
\text { todos os aspectos } \\
\text { culturais que se } \\
\text { constituem em } \\
\text { informações - atos, } \\
\text { dados, fatos, } \\
\text { conhecimentos. }\end{array}$ & $\begin{array}{l}\text { 2) Cultura, como } \\
\text { saber como: inclui } \\
\text { os aspectos } \\
\text { culturais que se } \\
\text { constituem } \\
\text { habilidades - ações, } \\
\text { participações, } \\
\text { comportamentos. }\end{array}$ & $\begin{array}{l}\text { 3) Cultura, como } \\
\text { saber por quê: } \\
\text { compreensão dos } \\
\text { valores básicos, das } \\
\text { atitudes e } \\
\text { suposições da } \\
\text { cultura; as razões } \\
\text { que fundamentam e } \\
\text { permeiam todos os } \\
\text { aspectos da cultura, } \\
\text { baseados em uma } \\
\text { dimensão crítica de } \\
\text { sua aprendizagem. } \\
\text { 4) Cultura, como } \\
\text { conhecer a si } \\
\text { mesmo: } \\
\text { autoconhecimento e } \\
\text { compreensão de } \\
\text { seus próprios } \\
\text { valores culturais. }\end{array}$ \\
\hline
\end{tabular}

\section{DISCUSSÃO}

Apesar da tarefa sobre o futebol, presente na seção "Desafio: tarefa comunicativa", p.196, contemplar a visão tradicional de cultura, uma vez que a tarefa pede informações sobre o sentido figurado dos termos futebolísticos, há espaço para as outras duas formas de se ensinar a cultura; a cultura como prática social e a intercultural. Cabe ao professor se sensibilizar para essas outras formas de ensino de cultura, a fim de desenvolver habilidades específicas com os alunos.

Ao perceberem o significado das expressões, os alunos podem destacar os comportamentos, as ações e as participações advindos dessas expressões por meio de uma peça teatral. Nesse caso, os aprendizes construirão suas falas utilizando as 
expressões futebolísticas em seus sentidos figurados em contextos de comunicação específicos. Assim, haverá a participação direta ou simulada dos aprendizes na vida diária das pessoas da cultura-alvo, de acordo com seus costumes e tradições, usando seus instrumentos e sua tecnologia, no caso as expressões futebolísticas, estabelecendo relações eficazes com elas.

Dessa forma, os alunos se capacitam para se adaptarem/integrarem à cultura dizerem e fazerem coisas à maneira das pessoas da cultura. Isso significa mudar seus comportamentos. Por outro lado, o professor sensibilizado interculturalmente pode desenvolver um trabalho que vai além do ensino tradicional da cultura e da cultura como prática social. Uma esfera de interculturalidade pode ser estabelecida a partir do momento que o aprendiz reflete sobre a sua cultura nativa $(\mathrm{C} 1)$ e a cultura-alvo (C2). Por exemplo, ao pensar se existem expressões futebolísticas em sua cultura nativa para não só compará-las à cultura brasileira, mas para refletir sobre um terceiro lugar advindo dessas duas esferas $\mathrm{C} 1$ e $\mathrm{C} 2$, o aprendiz poderá começar o seu entendimento no que concerne a o que é ser estrangeiro, a o que é ser o outro nesse novo espaço, pois tanto o professor como o aluno podem ser considerados "outros" nesse terceiro espaço intercultural.

Essa reflexão também é papel do professor e não somente do aluno. Cabe ao professor extrapolar as suas fronteiras, lendo obras e trabalhos que não estejam diretamente ligados ao seu trabalho, mas que acrescentem, de alguma maneira, em sua formação intercultural. Não menos importante, essa tarefa sobre futebol é oportuna no que se refere à desconstrução do estereótipo do "país do futebol". Nesse caso, a culturaalvo não apresenta aquela visão monolítica em que todos os brasileiros gostam e jogam futebol.

Existe uma variedade de fatores envolvidos nesse gostar ou não gostar do futebol, como a idade, gênero, origem regional, background étnico e classe social, devendo ser trabalhados em sala de aula. Assim, professores e alunos podem reconstruir o contexto de produção e recepção do texto dentro da cultura estrangeira (C2 e percepções de C2); construir com os alunos seu próprio contexto de recepção, i.e. encontrar um fenômeno equivalente em $\mathrm{C} 1$ e construir o fenômeno na $\mathrm{C} 1$ com suas próprias redes de significado; examinar o modo como as percepções de C1 e C2 em parte determinam as percepções que estrangeiros têm delas, i.e., o modo como cada cultura vê a outra, preparando o terreno para um diálogo que pode levar à mudança. 
A tarefa presente na seção "Almanaque Brasil”, p. 248-249, trata das novelas brasileiras. Nessa tarefa, percebe-se o ensino de cultura como prática social, uma vez que o aprendiz deve acessar a internet como um brasileiro que gosta de novela, ler o resumo semanal e contar para os outros colegas.

Contudo, mais uma vez, há espaço para a sensibilidade intercultural do professor. Para início de conversa, o estereótipo pode ser desconstruído, pois nem todos os brasileiros gostam ou assistem novelas. Outros estereótipos referentes às novelas também podem ser desconstruídos, como por exemplo, a existência de diversas emissoras que hoje também produzem novelas, ainda que prevaleça a qualidade e a credibilidade da emissora líder de audiência em telenovelas no Brasil. As próprias informações contidas no texto, "A novela brasileira: entre a tela e a vida real" (veja anexo), dá margens a outras desconstruções, como por exemplo, se a novela brasileira possui força absoluta no que concerne à influência na moda, nos bens de consumo e, principalmente, no comportamento das pessoas.

Esse aspecto cultural sobre a telenovela brasileira trata, como afirmamos anteriormente, da compreensão dos valores básicos, das atitudes e suposições da cultura, ou seja, as razões que fundamentam e permeiam todos os seus aspectos. Por que os brasileiros gostam tanto de novela? O aluno está fazendo uma observação ou uma interpretação? O aprendiz tem que demonstrar habilidades para inferir, generalizar, fazer hipóteses, ser objetivo. Ele tem que demonstrar curiosidade, tolerância e sensibilidade. Os professores devem estimular os alunos a interpretarem e tirarem conclusões, fazendo comparações com sua própria cultura e escrevendo com reflexão.

Assim, os alunos usam vigorosamente seus poderes de indução, análise e intuição para tirar conclusões sobre as informações ou experiências culturais. O papel do professor é o de questionar e fornecer informações. Por fim, o professor pode estimular o aluno a conhecer a si mesmo com base na reflexão sobre sua cultura $\mathrm{C} 1$ provocada pela cultura-alvo (C2) da tarefa. Qual é o programa de televisão mais assistido em seu país? Quais valores esses programas agregam no comportamento diário dos habitantes de seu país? Esse aspecto trata do aluno individualmente - seus valores, suas opiniões, seus sentimentos, seus questionamentos, suas reações, seus pensamentos e suas idéias, seus próprios valores culturais. Trata do autoconhecimento, ou seja, o processo que permite aos alunos entenderem a si mesmos e a sua própria cultura como um meio para compreenderem, adaptarem-se ou integrarem-se à nova cultura. São eles que decidem até que ponto aceitam, exploram ou tornam-se parte da cultura. Que importância os 
programas de televisão têm em sua vida? Como você se sentiu ao agir como um brasileiro durante a leitura do resumo semanal da novela?

Com isso, por meio de comportamentos/afirmações, os alunos podem demonstrar compreensão de sentimentos, seus valores, suas opiniões e atitudes. Isso faz com que eles se examinem e falem sobre si mesmos, escrevendo com reflexão. Por fim, os próprios alunos são o assunto em um processo de autodescobrimento orientado, à medida que estudam seus próprios valores e suas reações àqueles da cultura-alvo. Eles decidem se querem mudar ou não. O papel do professor é orientar.

\section{CONSIDERAÇÕES FINAIS}

Esse veículo, o livro didático, que estimula o aluno a fazer o seu julgamento de valor, está reforçando ou desconstruindo o estereótipo que ele tem da cultura brasileira? Com base no que foi apresentado, pode-se afirmar que depende do uso que o professor faz do livro didático. Tal uso desconstruirá o estereótipo se o professor apresentar sensibilidade à interculturalidade. "Só uma orientação intercultural consciente e fundamentada pode impedir que a aprendizagem de uma língua estrangeira reforce estereótipos e dificulte a verdadeira compreensão entre as culturas” (Zanatta, 2009).

Além disso, as tarefas culturais presentes no livro didático sensibilizam o aprendiz para uma visão de mundo crítica com base na interação da sua identidade cultural com a identidade cultural do outro? Nota-se que TB deu um passo significativo no que concerne à lacuna de livros didáticos de PLE que não apresentam diversidade de tópicos culturais.

Contudo, mais uma vez, a atuação do professor é essencial para que as tarefas sensibilizem o aprendiz para uma visão crítica de mundo. Reforça-se aqui a ideia do livro didático como suporte útil e significativo, e não como o protagonista do ensino/aprendizagem de PLE. O aluno se sente preparado para as reais situações de uso que envolvem a variante brasileira da língua portuguesa? Essas reais situações de uso refletem traços da competência intercultural do aprendiz? O aluno se sentirá preparado interculturalmente para se comunicar na variante brasileira da língua portuguesa em situações reais de uso quando as tarefas culturais forem trabalhadas com base em uma fundamentação teórica intercultural. Para que esse aluno se considere interculturalmente competente, ele precisará de um suporte, nesse caso, o livro didático, e de um bom orientador que o sensibilize para a reflexão intercultural. 
Este trabalho realça a necessidade de se fomentar uma formação mais abrangente do corpo docente em PLE. É preciso incitar o professor a ter um senso crítico no que se refere ao ensino de cultura em sala de aula. Para tanto, são necessários conhecimentos linguísticos, teórico-metodológicos e, principalmente, ambientes propícios para que os professores possam por em prática todas as suas reflexões.

Por fim, pode-se constatar que, por intermédio das tarefas presentes em TB, a cultura incita o aprendiz a galgar caminhos além daqueles limitados pela comparação entre suas experiências culturais. Estimula-se assim a criação de um lugar intercultural, onde o aprendiz de PLE se sensibiliza por meio de um olhar crítico e cultural, para a sua própria visão de mundo, ao descobrir-se capaz de aceitar e respeitar o outro no espaço da interculturalidade.

\section{REFERÊNCIAS}

ALMEIDA, M.J.A. \& DELL'ISOLA, R.L.P. (2008) Terra Brasil: curso de Língua e Cultura. Belo Horizonte: Editora UFMG.

BATISTA, A.A.G. (1998) "Um objeto variável e instável: textos, impressos e livros didáticos." In: ABREU, M. (eds.). Leitura, História e História da Leitura. São Paulo: Mercado de Letras.

BITTENCOURT, C.M.F. (1993) "Livro didático e conhecimento histórico: uma história do saber escolar." São Paulo. Tese de doutorado em História. Faculdade de Filosofia, Letras e Ciências Humanas, Universidade de São Paulo.

DINIZ, L.R.A.; STRADIOTTI, L.M.; SCARAMUCCI, M.V.R. (2009) "Uma análise panorâmica de livros didáticos de português do Brasil para falantes de outras línguas". In: DIAS, R.; CRISTÓVÃO, V.L.L. (eds.). O livro didático de língua estrangeira: múltiplas perspectivas. Campinas: Mercado de Letras.

FERREIRA, I.A. (1998) "Perspectivas interculturais na sala de aula de PLE." In: SILVEIRA, R.C.P. da (eds.). Português língua estrangeira: perspectivas. São Paulo: Cortez Editora. pp. 39-48.

FONTES, S.M. (2002) "Um lugar para a cultura". In: CUNHA, M. J. C. e SANTOS, P. (eds.). Tópicos em Português Língua Estrangeira. Brasília: EDUnB. p. 175-183.

GIMENEZ, T. (2002) "Eles comem cornflakes, nós comemos pão com manteiga: espaços para reflexão sobre cultura na aula de língua estrangeira." In: ENCONTRO DE PROFESSORES DE LÍNGUAS ESTRANGEIRAS, 10, Encontro de Professores de Linguas Estrangeiras. Londrina : APLIEPAR. p.107-14.

KRAMSCH, C. (1993) Context and Culture in Language Teaching. Oxford: Oxford University Press. 
KRAMSCH, C. (1998) Language and Culture. New York: Oxford.

LO BIANCO, J., LIDDICOAT, A \& CROZET, C. (1999) Striving for the third place intercultural competence through language education. Melbourne: Language Austrália.

MINISTÉRIO DA EDUCAÇÃO (2006) Certificado de Proficiência em Língua Portuguesa para Estrangeiros. Manual do Candidato. Brasília.

MORAN, P. (1990) “A Framework for Teaching Culture”. Material didático não publicado. Brattleboro: School for International Training.

OLIVEIRA, E.V.M.; FURTOSO, V.B. (2009) "Buscando critérios para avaliação de livros didáticos: uma experiência no contexto de formação de professores de português para falantes de outras línguas". In: DIAS, R.; CRISTÓVÃO, V.L.L. (eds.). O livro didático de língua estrangeira: múltiplas perspectivas. Campinas: Mercado de Letras.

Revista Veja. Texto (fragmento). (2008) "A novela brasileira: entre a tela e a vida real." 12 de fevereiro de 1997, ed. 1482. p. 51-56. Neuza Sanches, Gabriel de Lima, São Paulo: Editora Abril. In: ALMEIDA, M.J.A. \& DELL'ISOLA, R.L.P. Terra Brasil: curso de Língua e Cultura. Belo Horizonte: Editora UFMG. p.248-249.

SILVA, Benedicto. (coord.). Dicionário de Ciências Sociais. Rio de Janeiro: FGV, 1986.

UR, P. (1995) A Course in Language Teaching: practice and theory. Cambridge, Cambridge University Press.

ZANATTA, R. (2009). "Abordagens de ensino de cultura na aula de Português (brasileiro) para Falantes de Outras Línguas". In: Formação de professores de Português para Falantes de Outras línguas. Londrina: Eduel.

\section{OS AUTORES}

Henrique Rodrigues Leroy é licenciado pela Faculdade de Letras da Universidade Federal de Minas Gerais (FALE/UFMG). Tem experiência na área de EnsinoAprendizagem de Línguas Estrangeiras no Brasil e no exterior, com ênfase nas Licenciaturas de Língua Inglesa e Língua Portuguesa para Estrangeiros. É mestre em Letras, na área de Estudos de Linguagens, Ensino e Mediações Tecnológicas pelo Centro Federal de Educação Tecnológica de Minas Gerais (CEFET-MG), sendo integrante do núcleo de pesquisa em linguagem e tecnologia INFORTEC do CEFETMG, com ênfase na avaliação e no ensino-aprendizagem de português-língua estrangeira. Também é colaborador do Instituto Nacional de Estudos e Pesquisas Educacionais Anísio Teixeira (Inep-MEC), onde presta serviços na correção, elaboração e aplicação do Certificado de Proficiência em Língua Portuguesa para Estrangeiros (Celpe-Bras).

E-mail: henriqueleroy@hotmail.com 
Jerônimo Coura Sobrinho possui graduação em Letras (Francês e suas Literaturas) pela Universidade Federal de Minas Gerais (1994), graduação em Engenharia Civil pela Escola de Enga. Kennedy (1980), graduação em Letras (Inglês/Português e suas Literaturas) - Faculdades Metodistas Integradas Isabela Hendrix (1986), mestrado em Letras pela Universidade Federal de Minas Gerais (1998) e doutorado em Estudos Linguísticos pela Universidade Federal de Minas Gerais (2004). Atualmente é professor de Inglês, no Departamento de Linguagem e Tecnologia do CEFET-MG. Tem experiência na área da Linguística Aplicada e em Análise do Discurso. Atua nos seguintes temas: tenologias no ensino, avaliação de proficiência linguística, exame Celpe-bras, formação de professores, leitura em língua estrangeira, ensino e aprendizagem de Português como língua estrangeira.

E-mail: jeronimocoura@gmail.com

\section{ANEXO I}

\section{A novela brasileira: entre a tela e a vida real}

No Brasil, uma novela é um espetáculo muito poderoso - a família inteira se reúne para vê-la e é muito difícil desligar a TV ou tirar as crianças da sala. Segundo pesquisa sob a direção da professora Elza Berquó, do Centro Brasileiro de Análise e Planejamento (o CEBRAP), a novela influencia a vida dos brasileiros.

Em primeiro lugar, a novela possui uma força absoluta, quase irresistível, naquilo mais superficial - roupas e bens de consumo. Nesse terreno, a população compra e copia o que vê, o que explica o formidável faturamento das emissoras com publicidade.

Em segundo lugar, a novela é assistida por toda a família, e não apenas pelas mulheres, como muitas pessoas querem acreditar. Ela constrói a agenda para muitas discussões domésticas. Não dita comportamentos nem opiniões, mas, a partir de suas cenas e diálogos, leva os telespectadores a refletir e tomar partido.

Em terceiro lugar, a novela retrata um mundo completamente alienado do cotidiano da grande maioria da população brasileira. Um exemplo: nas novelas, apenas $48 \%$ dos personagens têm uma família tradicional com pai, mãe e filhos. Na vida real, esse número chega a $73 \%$. Embora seja uma obra de ficção, o mundo das novelas reflete o dia-a-dia dos autores dos folhetins eletrônicos no cotidiano urbano da Zona Sul do Rio de Janeiro, lendário pelo seu comportamento mais tolerante.

Em resumo: há mais sexo, mais beijos, mais crise no casamento nas novelas do que na vida real. Para sossego dos pais mais preocupados, a novela provoca discussão 
dentro da família, mas é raríssimo que alguém faça uma mudança radical em sua vida inspirado num personagem. De vez em quando, porém, isso acontece...

Revista Veja. Texto (fragmento). (2008) "A novela brasileira: entre a tela e a vida real." 12 de fevereiro de 1997, ed. 1482. p. 51-56. Neuza Sanches, Gabriel de Lima, São Paulo: Editora Abril. In: ALMEIDA, M.J.A. \& DELL'ISOLA, R.L.P. Terra Brasil: curso de Língua e Cultura. Belo Horizonte: Editora UFMG. p.248-249. 